\title{
Research of Organizational and Personal Factors of Professional Burnout of Personnel in a Consulting Organization
}

\author{
${ }^{* 1}$ Irina A. Rudaleva , ${ }^{2}$ Irina A. Kabasheva, ${ }^{3}$ Alina G. Khairullina \\ 1, 2, 3 Kazan Federal University \\ Email: rudiran@mail.ru Contact: +9600309682
}

Received: 21st October 2017 Accepted: 16th November 2017, Published: 31st December 2017

\begin{abstract}
Professional burnout is a process of gradual loss of emotional, cognitive and physical energy accompanied by symptoms of emotional and mental exhaustion and physical fatigue, personal standoffishness and a decrease in satisfaction level with the performance of work. There are three main groups of factors among the factors of professional burnout: personal, role and organizational. Professional burnout of employees of consulting companies is characterized by a decrease in the evaluation of competence and the value of their activities, and by emotional exhaustion. We evaluated the influence of various personal and organizational factors on the development of the professional burnout syndrome. The following factors (in descending order) have the greatest impact on this state of personnel: material satisfaction with work, marital status, health status, work experience of an employee in the company. The factor of "material satisfaction with work" is in direct proportion to the results, i.e. the more wages, the more often a person experiences a feeling of fatigue and "squeeze". This dependence is explained by the fact that career growth and, accordingly, the employee's salary depend on how effectively he or she works during a year, develops mandatory training programs and seeks to assume new roles and tasks. A new position requires both greater responsibility and additional workload.

The next important factor is the employee's marital status. The more stable the marital status, the less pronounced is the "squeezed lemon" syndrome. The more an employee works in a company, the less often he or she experiences chronic fatigue syndrome.

According to the staff opinions, organizational factors of professional burnout are inconsistencies between the work performed to wages, and also high load and multitasking. Role factors have little effect on the professional burnout of employees of consulting companies. The result of professional burnout is the growth of staff turnover in consulting companies.
\end{abstract}

Keywords: Professional Burnout, Personnel, Organizational, Personal and Role Factors.

\section{Introduction}

Let's investigate the presence of the professional burnout syndrome, as well as the factors that cause it, among employees of the audit and consulting firm.
Professional burnout is a syndrome that develops against the chronic stress and leads to the exhaustion of the emotional, energy and personal resources of the working person. The physical and neuropsychic loads that people experience during work are different depending on the type of activity. With single and small loads, natural mechanisms of body regulation are switched on, what helps to cope with the consequences of such loads. However, "self-regulation" does not always work, and professional burnout comes as a result of the internal accumulation of negative emotions without their "discharge" and "liberation". The paramount urgent task is to solve the problem of self-regulation of the employee's psychological state.

Thus, professional burnout is the process of the consequent loss of emotional, cognitive and physical energy, manifested in the symptoms of emotional and mental exhaustion and physical fatigue, personal standoffishness and a decrease in satisfaction with the performance of work.

\section{Methods}

We have selected such survey methods as questioning, factor analysis, and correlation-regression analysis with the use of Statistica software package. We conducted a study of the professional burnout level and the factors that determine it, based on the questioning of employees of a consulting company. A total of 54 employees were interviewed. The answers to the questions of the questionnaire made it possible to assess the gender, age, marital status, length of service, length of service in the company, position, educational level, frequency of overtime, material satisfaction with work, and presence of a professional burnout.

To diagnose the degree of expression of the "emotional burnout effect", the method of American psychologists Maslach C. \& Jackson S.E. was used. The questionnaire consisted of 22 statements reflecting the person's thoughts and feelings about his or her professional activity, and it has three evaluation scales: - "Emotional exhaustion" (manifested in the sensations of emotional overstrain and in the feeling of emptiness, the exhaustion of their emotional resources; a person feels that he or she can not give himself/herself to work as before);

- "Depersonalization" (associated with the emergence of an indifferent, negative and even cynical attitude towards people with whom it is necessary to contact by 
type of work, contacts with them become impersonal and formal);

- "Reduction of personal achievements" (manifested in a decrease in the evaluation of their competence, dissatisfaction with themselves, diminishing the value of their activities, negatively treating themselves as individuals, indifference to work).

The technique allows to estimate the intensity of negative feelings and thoughts, which characterizes the severity of the burnout effect. The development of "burnout" occurs for a long time, depends on the personal characteristics of the employee (lack of communication, shyness, emotional instability, low self-sufficiency, etc.) and the influence of production factors. Burnout develops earlier if an employee:

- Evaluates his/her work as insignificant;

- Is not satisfied with his/her professional growth;

- Lacks independence, believes that he/she is unduly controlled;

- Completely absorbed in his/her work (workaholic);

- Feels role uncertainty due to unclear requirements to him/her;

- Experiences an overload or, conversely, underload (the latter generates a sense of his/her uselessness).

\section{Results}

The main cause of professional burnout is the discrepancy between the personality and the work performed, as a result of which fatigue occurs, and the equilibrium state is disturbed [1].

There are several options for this discrepancy:

- A discrepancy between the requirements for the employee and his/her real capabilities;

- A discrepancy between the desire of employees to have a greater degree of independence in their work, to determine the ways and methods of achieving the results for which they are responsible, and the rigid irrational policy of the administration in the organization of working activity and control over it;

- A discrepancy between the efforts and the level of remuneration for the work. This discrepancy leads to the fact that an employee begins to feel the nonrecognition of his/her work, which leads to emotional apathy, a decrease in emotional involvement in the affairs of the collective, and emergence of a sense of injustice;

- A discrepancy between ethical values and the requirements that the work presents. The result is emotional tension that arose as a result of cognitive dissonance between thoughts and real actions.

There are three main groups of factors among those concerning a professional burnout: personal, role and organizational. The influence of a sense of self-worth in the workplace, opportunities for self-realization, and professional advancement on the problems of professional burnout has been studied by many scientists [2, 3, 4, 5, 6]. If an employee feels the importance of their activities, then he or she experiences less stress, is emotionally stable. If the work looks insignificant in his or her own eyes, then the syndrome develops faster. Its development is also facilitated by dissatisfaction with his or her professional growth, excessive dependence on the opinions of others and a lack of autonomy, or lack of independence of the employee. The lack of the possibility of further training and professional improvement of the employee also contributes to professional burnout; the employee feels that in his or her development helshe tramples on the spot.

Studies have shown that the conflict of roles and role uncertainty, as well as professional situations in which the joint actions of the employees are largely uncoordinated (there is no integration of efforts, there is competition) significantly influence the development of burnout $[4,7,8]$. Well-coordinated team work in the situation of distributed responsibility protects employees from the development of the syndrome of professional burnout [9]. High workload, tight regulation of the working time in the joint work of motivated colleagues contributes to the growth of efficiency, prevents the development of professional burnout.

The development of the syndrome affects many hours of uncertain work (unclear functional duties) or not receiving proper assessment from their head. Authoritarian style of leadership, when the boss does not allow the employee to show independence, deprives him/her of a sense of responsibility for their work and awareness of the significance, importance of the work performed contributes to the development of professional burnout and reduces the efficiency of employees' work.

Gradual formation of these symptoms of professional burnout in employees can lead to a kind of professional burnout of the organization as a whole [10, 11, 12, 13]. Signals of such a burnout is the presence of the same psycho-emotional symptoms in employees, behavioral manifestations inherent in the burnout syndrome. As a rule, this is due to the general pessimism in the organization, discontent with the results of work (certain events) expressed by employees [14, 15]. Researchers distinguish three main signs of professional burnout:

- Exhaustion;

- Personal standoffishness;

- Loss of own efficiency

Analysis with the breakdown by age structure showed that $48 \%$ of employees are between the ages of 24 and $26,22 \%$ from 27 to 29 , and $19 \%$ from $21-23,7 \%$ from 18 to 20 and $4 \%$ from 36 to 40 years. Almost half of the interviewed persons have a total work experience of 1 to 3 years, $29.63 \%$ of respondents have a work record of 3-5 years, and $18.52 \%$ of respondents have more than 5 years of work experience, as for the length of service in this company, then the largest number of respondents, namely $70.37 \%$ of them, worked in this organization for 1 to 3 years. So, in general the staff was very young. 


\section{Discussion}

According to the employees of the consulting company, the most significant causes of stress for them are:

- The discrepancy between the work performed and your wages;
- High load;

- Doing several things at the same time.

Questioning allowed to determine the level of emotional burnout of employees (Table 1).

Table 1. Degree of Emotional Exhaustion of Staff

\begin{tabular}{|l|c|c|c|c|c|c|}
\hline & \multicolumn{2}{|c|}{$\begin{array}{c}\text { Degree of Emotional } \\
\text { Exhaustion }\end{array}$} & \multicolumn{2}{c|}{$\begin{array}{c}\text { Degree of Expressiveness of } \\
\text { Depersonalization }\end{array}$} & \multicolumn{2}{c|}{$\begin{array}{c}\text { Severity Degree for the Effect of } \\
\text { Reduction of Personal Achievements }\end{array}$} \\
\cline { 2 - 7 } & Amount & $\%$ & Amount & $\%$ & Amount \\
\hline Critical & - & - & - & - & 10 & 18.52 \\
\hline High & 36 & 66.67 & 12 & 22.22 & 40 & 74.07 \\
\hline Medium & 18 & 33.33 & 36 & 66.67 & 4 & 7.41 \\
\hline Minimum & - & - & 6 & 11.11 & - & - \\
\hline $\begin{array}{l}\text { Overall } \\
\text { Result }\end{array}$ & 54 & 100 & 54 & 100 & 54 & 100 \\
\hline
\end{tabular}

According to the methods of Maslach, C., \& Jackson, S.E. [16] , the "emotional burnout effect" is pronounced if a high degree is observed in all three scales. There are 10 people $(18.52 \%)$ among the employees who have a high degree of burnout effect in all three categories.

Note that $66.67 \%$ of employees have a high degree of emotional exhaustion. It manifests itself in a feeling of emptiness, the exhaustion of its emotional resources. $74.07 \%$ of employees have a high degree for the effect of reduction of personal achievements (dissatisfaction with themselves, diminishing the value of their activities, negative attitude towards themselves as individuals, indifference to work).

Further, the causes and factors of professional burnout were identified. Employees were asked to assess the degree of severity of their condition at the end of the working day. It is a sign of chronic fatigue syndrome. The results indicate a high level of chronic fatigue of employees. Most of them (37.04\%) often feel depleted, $25.93 \%$ - very often, $22.22 \%$ - daily.

Then we evaluated the influence of various personal and organizational factors on the development of the syndrome of professional burnout. Evaluations of the statement "After work I feel like a squeezed lemon." were used as a dependent variable $\boldsymbol{Y}$. To determine the significant factors, a correlation matrix was built. It turned out that the most significant factors are: $\boldsymbol{x} \mathbf{2}$ (marital status), x6 (work experience in the company), $\boldsymbol{x} 7$ (material satisfaction with work), and $\boldsymbol{x} \boldsymbol{8}$ (health status).

The following model was obtained (Table 2, 3).

Table 2. Estimated Variables of the Model

\begin{tabular}{|c|c|c|c|c|c|}
\hline Dependent variables & Coefficient & Statistical Error & t-statistics & P-value & -ver \\
\hline const & 6,21302 & 0,715470 & 8,684 & 0.0023 & $* * *$ \\
\hline$X 2$ & -0.548817 & 0.170666 & -3.216 & $1.26 \mathrm{e}-05$ & $* * *$ \\
\hline$X 6$ & -0.386095 & 0.0794737 & -4.858 & 0.0003 & $* * *$ \\
\hline$X 7$ & 0,813609 & 0,207401 & 3.923 & 0.0336 & $* *$ \\
\hline
\end{tabular}

Table 3 .Summary Table of the Final Results and Tests

\begin{tabular}{|l|c|}
\hline \multicolumn{1}{|c|}{ Test Indicators of the Model } & Value \\
\hline Mean dependent variable & $3,814,815$ \\
\hline Sum of squared errors & 18.82249 \\
\hline R-square & 0.531174 \\
\hline F (4.6) & 13.87911 \\
\hline Logarithmic likelihood & -48.16652 \\
\hline Schwartz criterion & 116.2780 \\
\hline Standard deviation of the dependent variable & 0,870352 \\
\hline Standard error of the model & $0,619,784$ \\
\hline
\end{tabular}


Helix Vol. 8(1): $2372-2376$

\begin{tabular}{|l|c|}
\hline Corrected R-square & $0,492,903$ \\
\hline P-value (F) & $1,22 \mathrm{e}-07$ \\
\hline Akaike criterion & 106.3330 \\
\hline Hannan-Quinn criterion & 110.1684 \\
\hline
\end{tabular}

The regression equation was obtained:

$$
\mathrm{y}=6,21-0,54 \mathrm{x} 2-0,39 \mathrm{x} 6+0,81 \mathrm{x} 7-0,41 \mathrm{x} 8
$$

The model built at $53.12 \%$ explains the dependence for the formation of the state of the "squeezed lemon" feeling. The greatest influence on this state is provided by the factor "material satisfaction with work". This factor is in direct proportion to the resultant, i.e. the more wages, the more often a person experiences a feeling of fatigue and "squeeze." This dependence is explained by the fact that career growth and, accordingly, the employee's salary depend on how effectively he or she works during the year, masters mandatory training programs and seeks to assume new roles and tasks. A new position requires both greater responsibility and additional workload.

The next important factor is the employee's marital status. It turned out that the more stable the marital status is, the less pronounced is the "squeezed lemon" syndrome.

We also found that the more an employee works for a company, the less often he or she experiences chronic fatigue syndrome.

Respondents were asked to rank stress factors at work. The reasons for professional burnout (in descending order) were inconsistencies in the work performed, wages, high workload, multitasking, overtime, inadequateness of the work performed to the the qualifications, lack of clear job responsibilities, high responsibility, and human relations in a work team.

\section{Summary}

The main reason for feeling fatigue, exhaustion, the state of "squeezed lemon" after a working day, is a high workload in the workplace. The fact that most of the employees have a work experience in the company from 1 to 3 years, and no one has worked for more than 5 years, suggests that the company has a high staff turnover, which is due to the fact that employees "burn out" not withstanding the loads.

According to the data, women suffer from chronic fatigue syndrome four times more often than men. In the analyzed company, the bulk of the employees are women. Only women were included in the sample, that actualizes the issue of preventing burnout in this company.

\section{Conclusions}

HR-specialists, organizational psychologists, and business trainers should study the factors that cause the development of professional burnout in order to diagnose the development of the syndrome in time and provide the necessary assistance to employees.

The company needs to reconsider the organizational aspects of working hours and the burden on employees, as apart from personal factors, organizational factors also contribute to the development of burnout. These 2375 include: organization of working time, employee's workplace, and relationships in the work team. The emergence of the professional burnout syndrome is influenced by excessive working hours, regular involvement of a person in overtime work, work on weekends, frequent business trips. All this deprives employees of a proper rest.

It must be remembered that professional burnout can occur in a whole team. "Burnout" employees unite with colleagues who have similar problems; negative moods increase, and as a result, the quality of work decreases. The reasons for professional burnout in the team are often the organizational factors. Obviously, the consequences of collective burnout are deplorable. The loyalty of the personnel, the quality of work, the productivity of labor, and, as a result, the turnover of staff increase.

The syndrome of professional burnout is characterized by a feeling of dissatisfaction with yourself and the actions of surrounding people, indifference and even dislike of the profession and position. All these factors are not compensated by either a high salary or other benefits related to professional activity. Important in understanding this problem is that the syndrome of professional burnout can not usually be overcome by short-term rest or reduced load. The only solution is to change the position or even the type of activity. Therefore, it is necessary to exclude factors that could lead to its occurrence.

\section{Acknowledgments}

The work is carried out according to the Russian Government Program of Competitive Growth of Kazan Federal University.

\section{References}

[1] Grabe M. Burnout syndrome is a disease of our time. Why do people burn out and what can be done against this: translated from German - SPb .: Rech', 2008. - $96 \mathrm{p}$.

[2] Llera, J., \& Durante, E. (2014). Correlation between the educational environment and burn-out syndrome in residency programs at a university hospital. Archivos argentinos de pediatria, 112(1), 611.

[3] Nezhad, M. A. (2014). Investigating the relationship between the big five personality factors and professional burnout in the health care field. International Journal of Research in Organizational Behavior and Human Resource Management, 2(4), 176-188.

[4] Antoniou, A. S., Ploumpi, A., \& Ntalla, M. (2013). Occupational stress and professional burnout in 
teachers of primary and secondary education: the role of coping strategies. Psychology, 4(03), 349.

[5] Wang, H., Hall, N. C., \& Rahimi, S. (2015). Selfefficacy and causal attributions in teachers: Effects on burnout, job satisfaction, illness, and quitting intentions. Teaching and Teacher Education, 47, 120130.

[6] Shanafelt, T. D., Gorringe, G., Menaker, R., Storz, K. A., Reeves, D., Buskirk, S. J., ... \& Swensen, S. J. (2015, April). Impact of organizational leadership on physician burnout and satisfaction. In Mayo Clinic Proceedings (Vol. 90, No. 4, pp. 432-440). Elsevier. [7] Galęba, A., Bajurna, B., Marcinkowski, J. T., \& Gałązka, M. (2015). Professional burnout among doctors and nurses as a result of exposure to considerable stress at work.

[8] Craigie, M., Osseiran-Moisson, R., Hemsworth, D., Aoun, S., Francis, K., Brown, J., ... \& Rees, C. (2016). The influence of trait-negative affect and compassion satisfaction on compassion fatigue in Australian nurses. Psychological Trauma: Theory, Research, Practice, and Policy, 8(1), 88.

[9] Askhatova, L. I., Bulnina, I. S., Rudaleva, I. A., \& Kabasheva, I. A. (2015). Coaching as an Innovative form of Staff Development in Organisations. Mediterranean Journal of Social Sciences, 6(1 S3), 266.

[10] Arshava, I., \& Baratyns' ka, A. (2015). Role of positive values and personality traits in preventing of professional burnout among law enforcement officers. European Scientific Journal, 11(35).

[11] Shanafelt, T. D., Gorringe, G., Menaker, R., Storz, K. A., Reeves, D., Buskirk, S. J., ... \& Swensen, S. J. (2015, April). Impact of organizational leadership on physician burnout and satisfaction. In Mayo Clinic Proceedings (Vol. 90, No. 4, pp. 432-440). Elsevier.

[12] Willard-Grace, R., Dubé, K., Hessler, D., O’Brien, B., Earnest, G., Gupta, R., ... \& Grumbach, K. (2015). Panel management, team culture, and worklife experience. Families, Systems, \& Health, 33(3), 231.

[13] Parygin B.D. Socio-psychological climate of the team: ways and methods of study / edited by V.A. Yadov. - SPb .: Nauka, 2006. - 236 p.

[14] Lauermann, F., \& König, J. (2016). Teachers' professional competence and wellbeing: Understanding the links between general pedagogical knowledge, selfefficacy and burnout. Learning and Instruction, 45, 919.

[15] Jacquet, A., Grolleau, A., Jove, J., Lassalle, R., \& Moore, N. (2015). Burnout: Evaluation of the efficacy and tolerability of TARGET $1{ }^{\circledR}$ for professional fatigue syndrome (burnout). Journal of International Medical Research, 43(1), 54-66.

[16] Maslach, C., \& Jackson, S. E. (2013). A social psychological analysis. Social psychology of health and illness, 227. 